\title{
PRE-CONFERENCE WORKSHOP
}

\section{Building Collaboration with Faculty and Instructional Designers}

Beth Larkee Kumar, Graduate Theological Union

Dr. Kyle Schiefelbein-Guerrero, United Lutheran Seminary

\begin{abstract}
Librarians are often working together within the library, but collaborating with faculty and instructional designers can benefit your students, faculty, and staff. Many large libraries have whole teams working collaboratively, but in a theological library you might be working at a much smaller scale, with a limited budget. This pre-conference focused on approaches that a small team (one librarian and one instructional designer/faculty member) has developed to collaborate across their departments to build a suite of services and collections to serve their patrons. The workshop allowed time to develop a plan of action to bring away three concrete items on which to collaborate with the faculty or instructional designers at your school.
\end{abstract}

\section{BACKGROUND OF THE GRADUATE THEOLOGICAL UNION}

Founded in 1962 as a consortium of Protestant seminaries, Graduate Theological Union soon became an ecumenical hub of Protestants, Catholics, and Unitarian Universalist traditions, now comprising eight schools. The Common Library was established 
in 1969, merging the schools' individual library holdings into a single collection, a combined catalog, and eventually a single building. The GTU expanded its offerings to include the $\mathrm{PhD}$ and MA degrees, while the individual seminaries maintained degrees geared toward ministerial leadership (MDiv, etc.). The consortium's location near the University of California, Berkeley has provided for important exchanges with the "secular" disciplines. The Center for Jewish Studies, the GTU's first non-Christian center, opened in 1968, and was later followed by centers for Islamic and Dharma studies. Recently, the Center for Arts \& Religion and the Center for Theology and the Natural Sciences joined the GTU. In 2016 the MA and $\mathrm{PhD}$ programs were realigned to emphasize the interreligious and interdisciplinary nature of the GTU.

Even with such collaboration and excitement, the economic downturn and changes in mainline Protestantism in the late-2000s led to shifts in priorities. Many administrative services (financial aid, business office, human resources, information technology) became decentralized, and the total number of faculty members was slightly reduced. In the midst of all this, the library maintains its central role as the main hub of the consortium, even though numbers of the professional and paraprofessional staff had been lowered over the past decade. Because of the increased importance of online learning at the schools, the Digital Learning Department was created with Dr. Kyle Schiefelbein-Guerrero as its inaugural director.

The reduction in library staff required rethinking how public and user experience would be handled, as there were only 1.5 reference librarians, a reduction from three FTE. With less staff, the reference librarians had to be smarter about how they used the time on and off the desk. They cross-trained other librarians to fill in during instruction sessions or absences and taught theologians employed in other areas the basics of referral reference to cover the desk rather than close it. Beth Kumar, as department head, needed to do the majority of the outreach, creation of content, and advertising while at the reference desk.

\section{REASONS FOR COLLABORATION}

With the Digital Learning Department and the GTU Library as the 
two remaining shared services for the entire consortium, it made sense to collaborate. At its most basic, it saves time, as there is a shorter time-to-completion on our projects when we do not have to repeat each process, such as reaching out to the schools to schedule orientation sessions. Yet teamwork does not naturally happen; it requires intentionality and time for the team to coalesce. As a team of two, we can accomplish more together than each one separately. The biggest reason for collaboration is to draw on the breadth of experience and expertise in the different areas represented. Specifically, this expertise can be labeled by the three roles of Librarian, Faculty Member, and Instructional Designer/Technologist. In some cases, these roles are not necessarily three separate people, as a team member may fulfill two roles on campus.

Librarian: the "insider" who is professionally trained in information-seeking and literacy; knows the services offered; is most associated with the library; may or may not have a strong background in technology and/or educational theory.

Faculty Member: the "consumer" who tends to think about the library insofar as it connects with research and classroom assignments; subject matter expert who knows the material the best and teaches it in the classroom, but may not be fully aware of the library's offerings; may or may not have a background in educational theory.

Instructional Designer/Technologist: the "facilitator" who brings together various tools and techniques to assist the subject matter expert in course design; can recommend approaches to information literacy and library usage as they connect specifically to courses.

Each person has had different histories with the classroom and the library, the combination of which is more than a single person. This breadth can help answer questions about what went well and what could be improved in the library and classroom experience.

A goal of collaboration is to become dialogue partners for new ideas. One option for dialoguing may be a verbal brainstorming session. The location of these dialogues is as important as who the 
partners are. When not requiring disclosure of private material, most of our dialogues took place between questions at the reference desk during slow shifts. This location was key, as it is a central service point in the building, in proximity to various places that intersect our individual and joint work.

Observing the places allowed us to brainstorm how to resolve some issues we see daily, each from a particular perspective. It also allowed the non-expert to see the realm of the expert, providing suggestions that an "insider" may miss. When it came time to outline plans formally, we moved to a room with a touchscreen and whiteboard.

A final reason for collaboration is to broaden the user base through referrals. Although some overlap exists, each person in the collaboration works primarily with a different group of constituents: the librarian with those engaged in research (faculty and students), the faculty member with students, and the instructional designer with faculty. Bringing all three together provides information from as many students, faculty, and staff members as possible, especially as some users are unsure who should know what when assuming older divisions of jobs.

Each role may know something that is of value to the other two, like a particular book that is popular among several courses that may be a good candidate for having multiple simultaneous ebook connections. This cross-information allows a faster initial response, which is not quite "cross-training," as each person in the collaboration team could not function alone.

\section{APPROACHES TO COLLABORATION}

At the GTU, Beth and Kyle have implemented these nine examples of collaboration, but there are many more that may work at your institution.

\section{Face-to-face Orientations}

Previously, we were doing three separate parts of the orientation process at different times and in different buildings during orientation week. The registrar was doing ID cards, the library was doing orientation, and Moodle support (Digital Learning Department) did a Moodle orientation. Moving the ID cards to the Digital Learning 
Department allowed us to change the process to create a block of time for "one-stop shopping" with the students divided by program and degree. When the students arrive at the library building, they have their photographs taken and IDs printed by Kyle or his student assistant, which takes approximately one minute per student. The ID card printer computer is on a cart, so it can be moved into storage when it is not orientation week.

After receiving their card, the students move into the Collaborative Learning Space (described below) to hear the hour-long library orientation to library resources, services, and other essential information. Some residential students may have a brief tour as well. Finally, Kyle gives a fifteen-minute overview of Moodle. The threepart session takes roughly ninety minutes and has motivated more students to attend the library orientation if they want an ID card, which has increased attendance to almost all incoming students.

We offer make-up sessions during the first week of classes for those who cannot attend orientation week.

\section{Workshops (co-taught) and classes}

Over the past few years, we have expanded the workshop offerings and targeted them toward specific audiences. For example, workshops for faculty and future faculty are geared towards teaching and course design. Other workshops are intended for a general graduate audience, such as the popular Zotero workshop.

We evaluate each workshop and make changes every semester, based on feedback from participants or the lack of participants. Sometimes the material is relevant, but the title of the workshop, the time offered, or the mode (in person or online) needs to be changed. In addition to our co-teaching, we occasionally teach with other departments, such as the Professional Development Program (a support program for the PhD students) and CARe (Center for Arts and Religion).

Examples of some of our co-taught workshops include: Fake News, Effective Presentations, Building Assignments with Information Literacy, Zotero, and Technology for Teaching Religious Studies and Theology.

\section{Zoom and YouTube}

We use both Zoom and YouTube for live events, the former for interactive events (in-class instruction sessions, meetings, and individual 
research help with students at a distance), and the latter for broadcasting larger events and workshops that are open to all and designed to be watched at any time (the Zotero workshop). Kyle has set up our Zoom room (meeting code) numbers to match our telephone numbers, so the students use the same number to call reference as to meet with a librarian on Zoom.

\section{Moodle embedded roles}

The increase in online and distance students also provided an opportunity for the reference librarian to be "present" in the courses in an asynchronous way. Kyle created a specific role in Moodle for the librarian, which is a hybrid of the student and teacher roles. To maintain FERPA compliance, the librarian role can create certain digital artifacts in the system but cannot access any student data (except posts in the approved forums). The instructor requests that the librarian be added to the class so that the librarian can add materials and participate in discussions.

The librarian has a "sandbox" page on Moodle to create various modules that can be imported into classes. A popular module is the library overview video-quiz sequence, which contains four videos and four quizzes. The sequence utilizes conditional activities so that students must complete the videos and quizzes in order to finish the module. The instructor can see when students finish the module, and the librarian can assess any additional training needs through the quiz results.

\section{Room Reservations/Room Remodeling}

Since the library serves as the intellectual and cultural hub of GTU, it only made sense to place our collaborative tech-enabled classroom in there. The GTU had secured a grant from the Arthur Vining Davis Foundation, originally to replace the outdated library computer lab with another computer lab. When Kyle came on board, the project was expanded to transforming the room into a flexible learning space, with movable furniture, a large touchscreen, and video conferencing equipment. Kyle attended a half-day pre-workshop at Educause about learning spaces to solidify the plans. Kyle and Beth took field trips to other libraries (particularly the remodeled spaces at the University of California, Berkeley) to see how furniture and technology were being used, including mobile whiteboards which we implemented 
throughout the library.

As a way to promote the use of the upgraded classroom, which we call the Collaborative Learning Space (CLS), we requested from the dean and registrar that the required doctoral departmental seminars and the MA research methods course be scheduled there. In return, the library would schedule a reference librarian at the desk (which is directly outside the classroom door) during and for an hour after the class, so that research help can be directly connected with classroom activities. This has also provided opportunities for the reference librarians to visit the classes themselves because of the visibility.

The popularity of the CLS had two consequences. First, we had to establish a policy on which classes and events could use the room. The space must still be open for library instruction sessions and workshops, so it cannot always be scheduled for regularly-scheduled classes. The policy dictates what has priority to use the room, which has worked with few glitches over the past two years. Second, faculty members wanted the other classrooms and study spaces upgraded with similar features. The GTU president was able to secure a larger grant that enabled us to transform a classroom, two study spaces, and a conference room, and provide additional technology for three additional rooms. The two study rooms and the Digital Learning Lab can be reserved online by students and faculty through the LibCal software. The CLS and library conference room calendars are managed manually because of the priority policy.

\section{Technical support (physical rooms and software)}

As mentioned in the introduction, "cross-information" is an important reason for collaboration. This is especially true when it comes to supporting the learning spaces, both the software and the physical furniture. With the CLS as the model, the rest of the learning spaces were designed similarly, meaning that it is necessary to be trained on one space to know how to use and support the others. The touchscreens with onboard computers and the regular screens with NUCs all have the same software and passwords, and every system includes easy instructions for video conferencing. This consistency enables more people to support the systems, even at the basic level.

This support includes configuring the room's layout to optimize learning. The tables are unlocked and unplugged so that they can 
be placed in different arrangements, and then they are locked and connected again. Patrons are asked about room layout when reserving the larger rooms. When orientations and library instruction occur in the CLS, extra tables and chairs are removed to lessen any distractions.

\section{Chat/reference services}

We have had librarian chat services on the library webpages for a while now but more recently integrated the chat into Moodle. The Ask-a-Librarian chat appears on the Moodle homepage, all course pages, and the help pages. Our statistics show that last year, nearly a quarter of all chat questions came via Moodle, along with an overall increase in chat questions each year. Sixty-three percent of chat questions still come directly via the library website, with the remaining $13 \%$ coming from Summon (the discovery layer) and LibGuides.

While clearly labeled with the words "Library Resources" and information about chatting with a librarian, we get a few students who are surprised that Beth or another librarian replies, as some expect a Moodle support person. For this reason, we have taught librarians to answer basic Moodle questions-such as "why can't I see the syllabus?"-questions that can be answered without any access to student data. However, the majority of the questions are reference or research questions, related to the assignments the students are trying to complete.

Conversely, Kyle has been cross-trained in basic reference skills. Although not a librarian, he can answer reference desk questions and knows when to refer students to a librarian when they need a more time-intensive research session. This is a tremendous asset because some questions begin as a standard technology question and then develop into a bigger information need.

\section{Advertising}

As with many of our activities before collaboration, we were completely siloed when it came to advertising our events. Moodle workshops, course design workshops, professional development workshops, and library workshops were advertised without a comprehensive marketing plan. Some workshops were listed on various websites, others sent to student email lists, others advertised with print signage, and some workshops only advertised by emailing faculty directly with a request to forward to their students. Our 
branch library had separate workshops and separate advertising, and we did not advertise on the GTU's social media presence at all.

We worked to combine all workshops into a single brochure for the semester, including workshops taught online and at the branch library. These were arranged by topic and date and given to all new students at orientation, and a LibGuide was created for most topics. We coordinated with campus marketing to advertise the ones with broad, general appeal on the campus social media platforms. We continued to advertise with print posters until recently when we replaced our bulletin board with a digital display. But most importantly, we added all the workshops to the campus-wide event calendar on the GTU website, so people who are not necessarily looking at the library homepage will see each workshop. Our workshops are free and open to the public, so while we primarily have an audience of GTU students, we do draw people in from the UC Berkeley campus and members of the community.

A major benefit of having these open conversations with our colleagues about what workshops they are offering provides two incentives. First, we (individually) duplicate our teaching less, and offering a face-to-face and an online workshop on the same topic is less prep work. We record the online workshop and keep it posted for the future, so more people have access to the material and the associated LibGuide, without a lot of extra effort on our part. Second, the conversations around workshops have removed some of the silos between departments, and we find ourselves team-teaching workshops more. One example of this is the collaboration between the library and our Professional Development Program; we designed a workshop on Careers in Libraries, and specifically discuss using their degrees to become a theological librarian. The workshop has been well attended by students who are unsure if a traditional teaching job is something they want but are considering all areas in academia.

\section{Collection Development}

As needed, we suggest purchases for faculty and our professional development that normally would fall outside of the scope of our collection development policy, which is primarily in Religion, Theology, and Philosophy. These could include design books, library 
architecture and space planning, Adobe software manuals, library instruction, and information literacy books, and they are purchased as ebooks when available. Additionally, as we get to know the courses and faculty, we will suggest books out of scope. These recommendations are based on courses where we have helped students/faculty, as in the case of biographies or fiction (areas where we do not collect much) or where we know there is higher-than-average demand, such as a book that is on the required list for three classes.

\section{CONCLUSION}

As we continue our work, the goal has been to expand our network of collaboration to other members of the GTU. This is not only important because we believe so strongly in collaboration, but it is also done out of necessity. When we presented our pre-conference workshop in Vancouver, we were in our positions as described throughout this article. After returning from the conference, we have both changed in our positions at the GTU. Beth has shifted in her responsibilities to become the lead librarian on user experience, the website, and online learning and shifted away from the management of the print collection and traditional reference desk duties. Kyle has left the GTU for a full-time faculty position elsewhere. The new Director of Digital Learning, who trained with Kyle for an entire month before taking over, will be included in the collaboration network.

Another goal of our collaboration is to help others with what we have learned and done. The workshop slides with images of our spaces are included at: https://libguides.gtu.edu/collaborate. In addition, we provide some questions for you to start or revise your own institution's collaborations.

\section{QUESTIONS TO GET STARTED ON YOUR PLAN:}

- Who at your library will be involved?

- Who are your contact people outside of the library?

- Do you regularly meet up with these people, or would you arrange a separate time?

- What resources and tools are needed, and what training is required? Examples: Zoom, Moodle, LibCal/LibGuides, Camtasia /Captivate, Adobe Premiere. 
- Are you in a multicampus/multilibrary situation? If so, will you involve the other campus?

- How will you work across departments?

- Do you need permission to begin these conversations?

- How will you report the progress?

- Who needs to know? Your faculty, deans, president, or trustees?

- Should you report accomplishments for accreditation?

- Are there budget implications? Some considerations: headset with microphone, webcam, software, training/webinars, printing, outreach event with faculty, additional people for reference desk coverage? Who will install any hardware that is purchased?

- How often will you meet with your collaborators? Will you have formal meetings, or informal check-ins and email regularly?

- How will you coordinate workshops, orientations, or classes in advance to avoid conflicting times?

- What do you want your outcomes to be?

Start small when you begin developing your plan: List three collaborations you would like to implement at your campus and list three specific tasks to do first.

\section{BIOS}

Beth Larkee Kumar was Head of Reference Services at the Graduate Theological Union Library in Berkeley, CA, managing the reference desk, the reference collection, instruction, and the library's website. She recently changed duties to become the Learning and User Experience Librarian, shifting her priorities to online learning, the user experience, and managing the library's website, guides, and marketing. Beth has been at the GTU for the past five years, but has previously been in academic libraries in Colorado, Illinois, and Virginia, ranging in size from giant flagship institutions to tiny private colleges. She holds both an MLIS and a Masters of Education (EdM) in Educational Organization and Leadership in Higher Education from the University of Illinois.

Kyle Schiefelbein-Guerrero was Director of Digital Learning and Lecturer in Theology and Educational Technology at Graduate Theological Union. He was responsible for the consortium's learning management system, course design workshops, faculty devel- 
opment, and teaching a doctoral seminar on digital pedagogy. He earned his $\mathrm{PhD}$ in Liturgical Studies and Systematic Theology from GTU and has additional training from Educause and the Online Learning Consortium. He is currently Assistant Professor of Worship and Liturgy at United Lutheran Seminary in Pennsylvania. Starting in January 2020, he will be serving as co-editor of the journal Teaching Theology \& Religion. 